\title{
Diagnostic and age composition of excess mortality associated with the New Year holidays in Russia
}

\author{
Alexander V. Nemtsov ${ }^{1}$, Timur A. Fattakhov ${ }^{2}$ \\ 1 National Research Center of Narcology of the Ministry of Health of the Russian Federation, Moscow, 119002, Russia \\ 2 National Research University Higher school of economics, Moscow, 101000, Russia
}

Received 3 August 2021 • Accepted 7 September 2021 • Published 8 December 2021

Citation: Nemtsov AV, Fattakhov TA (2021) Diagnostic and age composition of excess mortality associated with the New Year holidays in Russia. Population and Economics 5(4): 1-20. https://doi.org/10.3897/popecon.5.e72550

\begin{abstract}
Statistics show that in many countries of the world holidays are associated with an increase in morbidity and mortality; this is especially pronounced during the New Year and Christmas period. This article presents an estimate of the excess number of deaths in Russia during the January holidays in 2011-2019 by main classes of causes of death and by age groups.

The study relies on the Rosstat dataset of 16.83 million individual non-personalized death records referring to 2011-2019. The authors of the paper estimate excess mortality for each cause and age group as the difference between actually observed mortality and the LOWESS moving average calculated for non-holiday period, extrapolated to the holidays.

The calculations showed that the period of excess mortality lasted from January 1 to January 22 with a maximum on January 1. Over 22 days, excess mortality in 2011-2019 amounted to 89.0 thousand cases or $8.4 \%$ in relation to mortality on non-holidays; excess mortality on January 1 amounted to 11.4 thousand cases. In contrast to mortality from diseases of the circulatory, respiratory, and digestive systems, the contribution of which to excess mortality was proportional to their prevalence on non-holidays, proportion of excess mortality from external causes almost doubled ( $23.6 \%$ versus $12.7 \%$ on weekdays). January 1 saw the highest excess mortality from external causes, including that of alcohol poisoning, homicide, and suicide, in all age groups; on January 2 the highest increase was observed in mortality from diseases of the circulatory system; on January 9 and 10 - from the pathologies of the respiratory and digestive systems.

January holidays in Russia are associated with significant excess mortality, primarily as a result of the abuse of strong alcoholic beverages. Informing the population about the fatal consequences of such a consumption regime and a decrease in the availability of strong alcohol, the maximum sales of which falls on December, can reduce the damage during the January holidays.
\end{abstract}

\section{Keywords}

January holidays, excess mortality, alcohol poisoning, murders, suicides, age-specific mortality rates, Russia

JEL codes: I1, J1

Copyright Nemtsov AV, Fattakhov TA. This is an open access article distributed under the terms of the Creative Commons Attribution License (CC-BY 4.0), which permits unrestricted use, distribution, and reproduction in any medium, provided the original author and source are credited 


\section{Introduction}

An analysis of statistical data, including Russian, has repeatedly shown an increase in mortality during the New Year and Christmas period in many countries of Christian culture. For example, in the USA in Los Angeles in 1985-1996 mortality from cardiovascular diseases was highest in December-January (Kloner et al. 1999). The authors linked excess mortality to excessive stress during the holidays. Similar observations were later made in other studies: the peaks in the number of deaths due to heart disease occurred at Christmas and the New Year, and between these holidays, mortality decreased for two to three days (Phillips et al. 2004). Comparison of holiday losses revealed that the largest peak in mortality occurs at Christmas, followed by the New Year, and then, with a significant distinction, four more holidays (Thanksgiving Day, Independence Day, Labour Day and Memorial Day (Phillips et al. 2010)). A similar phenomenon was observed in Europe, for example, in England (Newcastle): in 1986-2000 at the New Year, but not at Christmas, mortality from cardiovascular and respiratory diseases increased. The described effect is observed precisely at the New Year holidays: no such dynamics were found at Easter (Milne 2005). In the United States, at the New Year, there is also an increase in suicides (by 18\%) and, even more significantly, in homicides (by 65\%). On other holidays, the number of suicides declines, and the number of homicides increases, but not so significantly (Bridges 2004). These papers are adjoined by another study carried out in England (Oxford) basing on the information about non-fatal self-inflicted harm in patients of trauma centers. The analysis shows a decrease in the number of self-inflicted harms in patients with problems in partner relationships 3 days before Christmas and an increase - in the first day of the New Year; it was also found that at the New Year there is a significant increase in self-inflicted harms under the influence of alcohol (Bergen and Hawton 2007).

Among the factors of increase in the number of deaths during the New Year and Christmas holidays, a number of authors nominally, without analysis, name overconsumption of food and alcohol, a decrease in the quality of medical care and an underestimation of danger in the event of an illness, leading to the postponement of seeking medical help. In addition, an increase in morbidity due to low outdoor temperatures is cited as the cause of the increase in mortality. However, the latter factor can be excluded, since, in New Zealand, for instance, where these holidays occur in summer, the number of deaths also increases during Christmas and the New Year (Knight et al. 2016). The data coming from the Western countries also points to the alcohol factor as one of the variables shaping the situation.

The causes of death at the New Year sometimes refer to exotic phenomena. In the southern United States (for example, Florida: (Rapkiewicz et al. 2014)) and in South America (for example, Puerto Rico: (Rodriguez and Mirabal-Colon 2004)), some deaths are caused by falling bullets as a result of shooting into the sky on New Year's Eve. In many countries, people are injured, sometimes severely and fatally, when New Year's fireworks are set off.

The described effects are also observed on Russian data: for example, one study (Barabash et al. 2010) shows an increase in cardiovascular and general mortality on January 2-5 in the city of Kemerovo. The maximum total mortality in the entire country is recorded in January (Nemtsov 2017). Marat Zhaksymbaev described the maximum number of murders in January (Zhaksymbaev 2012), and within this month the peak falls on January 1 (Nemtsov 2019; Nemtsov et al. 2021), which correlates well with mortality from alcohol poisoning on that day. Excess mortality is recorded not only at the New Year, 
but also on the days of the other four out of nine Russian public holidays (Nemtsov et al. 2021). At the same time, the maximum increase is observed during the New Year holidays: the total increase was 113.6 thousand people in total for 2000-2017 with a maximum on January 1 (35.6 thousand). It is also shown that after 2005, when the duration of the New Year holidays increased sharply, the dynamics of mortality did not change, the maximum remained on January 1 . Thus, the duration of the holidays did not have a significant effect on excess mortality.

\section{Data and research methods}

This study is epidemiological, retrospective, non-selective; the latter enables providing estimates without evaluating the statistical significance of the observed differences. The authors analyze not relative indicators, but absolute numbers of deaths, which more convincingly shows the size of losses. The paper considers the time series of the daily number of deaths from January 1, 2011 to December 31, 2019; this states for a total of 16.77 million deaths (an average of 5.1 thousand per day, varying from 4.3 to 7.0 thousand). In addition to the total number of deaths, the authors trace the distribution of deaths by the main classes of causes of death in accordance with ICD-10, distinguishing the following groups: certain infectious and parasitic diseases (A00-B99), neoplasms (C00-D48), diseases of the circulatory system (I00-I99), diseases of the respiratory system (J00-J99), diseases of the digestive system (K00-K93), external causes of morbidity and mortality (V01-Y98), and all other causes of death. In addition, three socially significant causes of death are analyzed separately: alcohol poisoning (X45, Y15), homicide (X85-Y09), and suicide (X60-X84). The authors considered accidental alcohol poisoning in accordance with ICD-10 as the sum of X45 (accidental alcohol poisoning) and Y15 (alcohol poisoning with undetermined intent) causes. This is due to the fact that in recent years in Russia there has been a sharp increase in the number of deaths from alcohol poisoning with undetermined intent, which is probably determined by erroneous coding of some of the deaths. The study used data on the deceased according to the actual date of death. Age analysis was carried out in five groups: 0-14, $15-39,40-59,60-74$ and $75+$ years (table 1). The calculations are based on the individual non-personalized data of Rosstat.

For the convenience of calculations, events without an exact date of birth or death ${ }^{1}(54.8$ thousand), as well as cases of death on February 29 (9.6 thousand), were excluded from the study.

A set of data on the daily number of deaths in 2011-2019 was divided into annual segments, which were summed up daily ( $\mathrm{n}=365$ days), and this new summarized series became the basis for subsequent analysis. When considering the overall mortality rate, the focus is on the four January holidays in Russia: the New Year (January 1), Orthodox Christmas (January 7), Old New Year (January 14), and Epiphany (January 19). In addition, when discussing the indicators, the authors take into account - without special analysis - Defender of the Fatherland Day (February 23), International Women's Day (March 8), Spring and Labour Day (May 1), Victory Day (May 9), Russia Day (June 12) and National Unity Day (November 4). When assessing the dynamics of mortality by causes, only January holidays are considered.

1 Dates with a specific day, month, and year of birth or death are considered to be exact dates. 
Table 1. Distribution of deaths by cause and age in 2011-2019

\begin{tabular}{|c|c|c|c|c|c|c|}
\hline & & $\begin{array}{c}\text { Amount } \\
\text { (thousand) }\end{array}$ & $\begin{array}{l}\% \text { of } \\
\text { total }\end{array}$ & $\begin{array}{l}\text { Average } \\
\text { per day }\end{array}$ & $\begin{array}{l}\text { Minimum } \\
\text { per day }\end{array}$ & $\begin{array}{c}\text { Maximum } \\
\text { per day }\end{array}$ \\
\hline \multicolumn{7}{|c|}{ Causes of death } \\
\hline 1 & $\begin{array}{l}\text { Diseases of the circulatory } \\
\text { system }\end{array}$ & 8453.6 & 50.4 & 23160.7 & 1915 & 3794 \\
\hline 2 & Neoplasms & 2655.7 & 15.8 & 7276.0 & 673 & 946 \\
\hline 3 & $\begin{array}{l}\text { Diseases of the respiratory } \\
\text { system }\end{array}$ & 624.8 & 3.7 & 1711.8 & 105 & 324 \\
\hline 4 & $\begin{array}{l}\text { Diseases of the digestive } \\
\text { system }\end{array}$ & 1473.3 & 8.8 & 4036.5 & 339 & 648 \\
\hline 5 & Infectious diseases & 301.6 & 1.8 & 826.3 & 52 & 133 \\
\hline 6 & Other causes & 1729.9 & 10.3 & 4739.6 & 123 & 1088 \\
\hline 7 & External causes & 1535.7 & 9.2 & 4207.3 & 295 & 1232 \\
\hline & Total & 16774.7 & 100.0 & 45985.1 & & \\
\hline \multicolumn{7}{|c|}{ Among external reasons } \\
\hline 8 & Alcohol poisoning & 149.0 & 0.9 & 45.3 & 16 & 203 \\
\hline 9 & Homicide & 105.1 & 0.6 & 32.0 & 7 & 147 \\
\hline 10 & Suicide & 219.3 & 1.3 & 66.8 & 24 & 136 \\
\hline \multicolumn{7}{|c|}{ Age of the deceased, years } \\
\hline 11 & $0-14$ & 165.1 & 1.0 & 452.3 & 16 & 218 \\
\hline 12 & $15-29$ & 367.7 & 2.2 & 1007.5 & 35 & 298 \\
\hline 13 & $30-44$ & 1284.2 & 7.7 & 3518.2 & 277 & 730 \\
\hline 14 & $45-59$ & 2775.2 & 16.5 & 7603.3 & 614 & 1539 \\
\hline 15 & $60-74$ & 4671.5 & 27.8 & 12798.8 & 1145 & 1943 \\
\hline 16 & $75+$ & 7511.0 & 44.8 & 20578.0 & 1782 & 3175 \\
\hline & Total & 16774.7 & 100.0 & 45958.1 & & \\
\hline
\end{tabular}

To create a pivot point for January 1, the usual series of indicators from January 1 to December 31 were rearranged so that January was in the middle of the series: the year was constructed from July 1 to June 30. The rebuilt series were duplicated and cleared of holidays and the days immediately adjacent to holidays, characterized by a relatively high mortality rate. In addition, artifacts of the last and first days of the month were removed from the series. After that, on the basis of the obtained series, the authors constructed a LOWESS moving average (LOcally WEighted Scatter-plot Smoother, locally weighted polynomial regression; (Cleveland and Devlin 1988)). The choice in favour of LOWESS with a bandwidth of 0.03 was made by comparing a set of other non-holiday series descriptions. All of them, as well as the leastsquares line and the LOWESS moving average with other bandwidths lied below LOWESS, which increased the excess mortality estimate (the quadratic and cubic polynomials increased the excess mortality estimate by $3.4 \%$ and $4.7 \%$, the fifth-degree polynomial - by $2.9 \%$; the line of least squares sometimes coincided with LOWESS-0.03, but never lied higher); the authors settled on LOWES- 0.03 as the lowest estimate of excess mortality. Holidays and artifacts gaps in the new series were filled based on linear regression predictions. The LOWESS of the second series, rebuilt in this way, applied to the original data, served as an extrapolation of the 
level of non-holiday mortality on holidays; the difference between these series is interpreted as excess mortality. The observation period for excess mortality was limited to the last day when the observed values after the maximum exceeded LOWESS values. The monthly indicators of consumption of vodka and wine in 2018-2019, used in the last section, are taken from the Rosstat website (Retail sale of alcoholic beverages in volume terms).

\section{Results}

\section{Dynamics of indicators of total mortality}

Fig. 1 shows the total mortality series from July 1 to June 30, as well as the LOWESS moving average for non-holidays with linear extrapolation to holidays. In this figure, attention should be paid to the peak-minimums on the last day of each month and the following peak-maximums on the first day of the next month. These are artifacts of registration of deaths in the last days of the month with their transfer to the next period. It is important to emphasize that the December 31 lowest peak is no different from random fluctuations, which means that the January 1 peak is clear of the December 31 artifact (as it will be seen from the analysis below, it is almost clean). This is most likely due to the atmosphere at the end of one year (increased attention to reporting) and the beginning of the next (long holidays). Another important element is the arrangement of the peaks on holidays, with the exception of November 4 (National Unity Day) and June 12 (Russia Day). Maximum excess mortality is observed on January 1 - this is the annual maximum mortality rate in Russia.

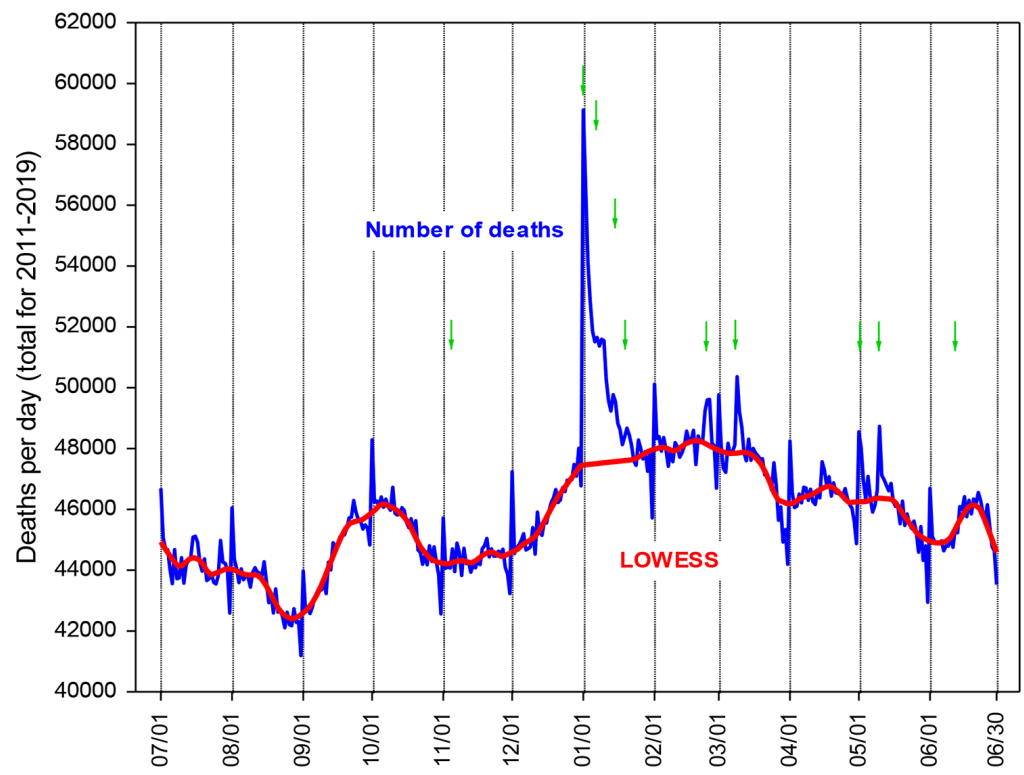

Fig. 1. The daily number of deaths in Russia, the sum of the indicators for 2011-2019 (blue line) and the moving average LOWESS for non-holidays, extrapolated to holidays (red line). Note: The vertical dashed lines indicate the first days of the months, green arrows indicate the main holidays, sequentially: November 4; January 1, 7, 14 and 19; February 23; March 8; May 1 and 9; June 12. Source: authors' calculations based on modelling and Rosstat data. 
For a detailed analysis of January mortality in Fig. 1, we enlarge a fragment from December 18 to February 5 (Fig. 2). On this figure, we compare the number of deaths on December 31 and January 31.

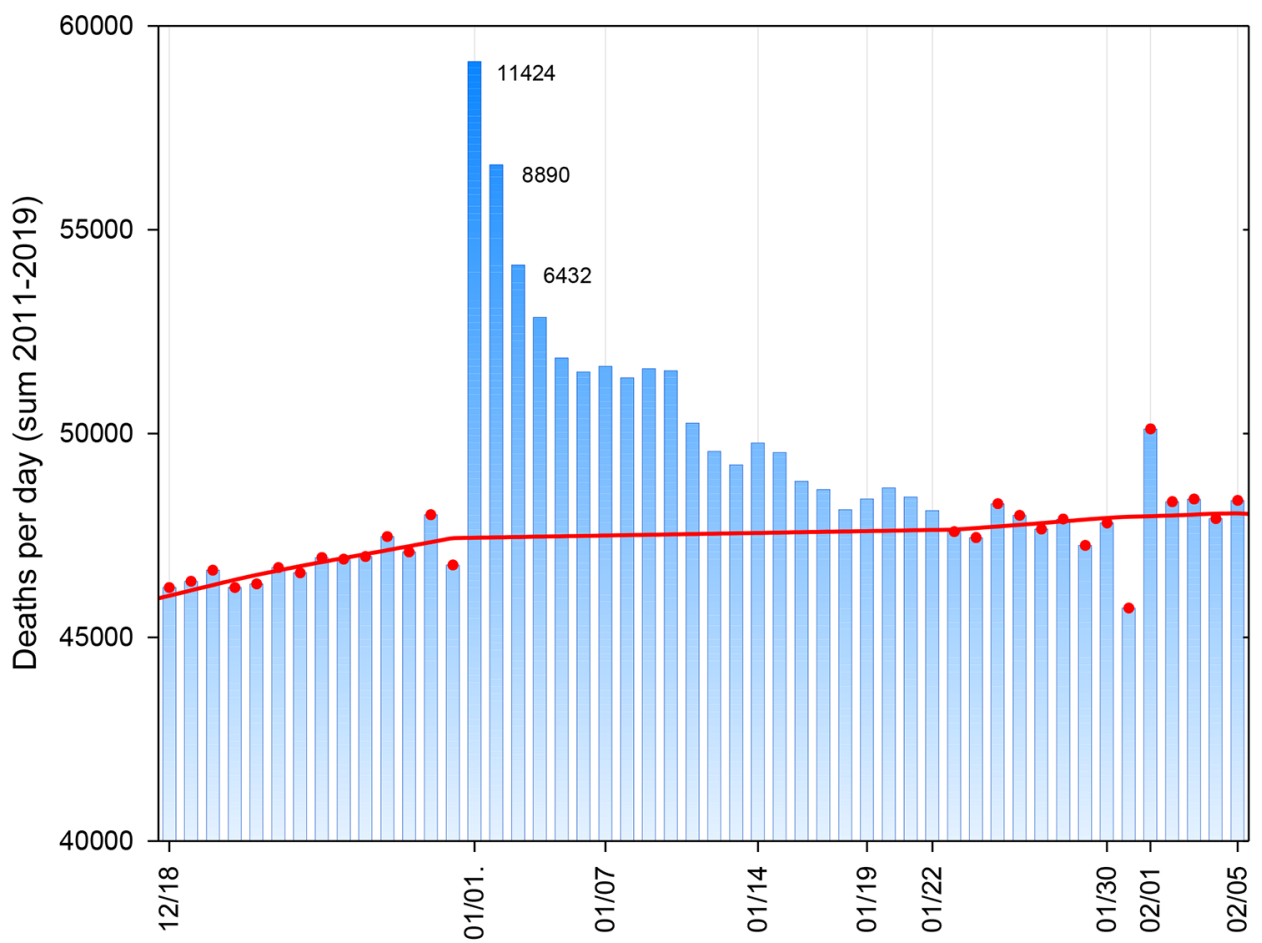

Fig. 2. The daily number of deaths in Russia from December 18 to February 5, the sum of indicators for 2011-2019 (blue bars) non-holidays and the LOWESS moving average extrapolated to holidays (red line). Note: Non-holidays are marked with red dots. Major holidays, as well as the end of the excess mortality period (January 22) are marked with dotted lines and the date on the abscissa. The numbers on the graph correspond to the excess deaths estimates for January 1-3. Source: authors' calculations based on modelling and Rosstat data.

On the graph, the LOWESS line divides deaths on holidays into those that would happen regardless of holidays (below LOWESS), and the excess deaths due to holidays (above LOWESS). The latter can be calculated by subtracting the series of LOWESS values from the series of the actual number of deaths during the holidays. For January 1 this is: total number of deaths minus LOWESS value (59.1-47.7 = 11.4 thousand deaths). Thus, the excess mortality on January 1 for the nine considered years is 11.4 thousand, and from January 1 to $22-70.3$ thousand, or an average of 7.8 thousand deaths annually. This means that $6.7 \%$ of the total number of the occurred deaths can be attributed to excess mortality due to the January holidays. A similar calculation scheme will be used to estimate excess mortality due to specific causes and ages. But first, January losses ought to be broken down into four separate holidays. This can be done on the assumption that after January 1-5, mortality would decline exponentially if there were no other holidays (Fig. 3). 


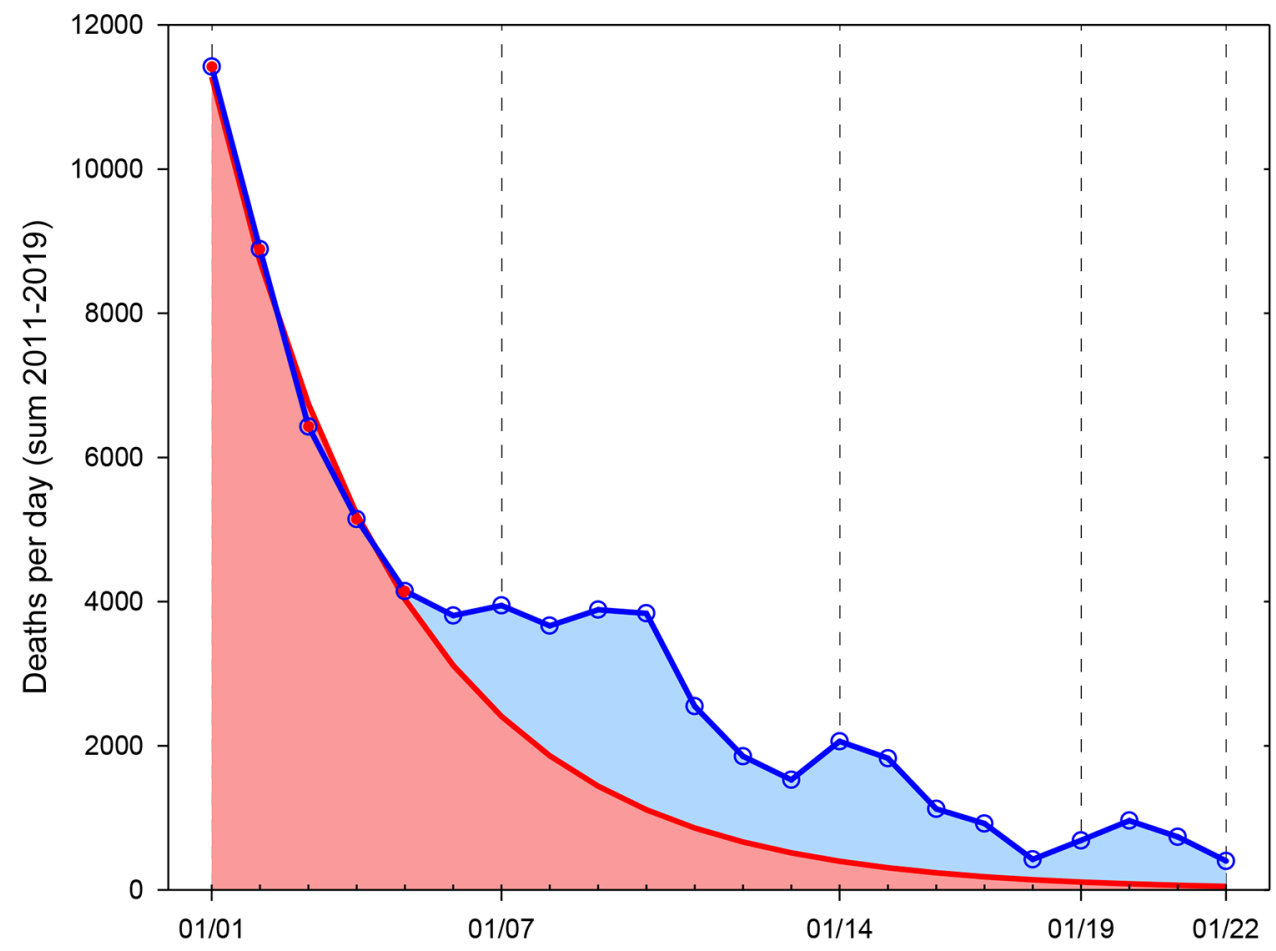

Fig. 3. Structure of excess deaths on January 1-22, depending on the holiday, sum of indicators for 2011-2019. Note: The blue line shows the dynamics of the total number of deaths, the red line is the exponent plotted for January 1-5 (days are marked with red dots on the line). The red field is excess mortality due to the New Year, the blue field is excess mortality due to the other three holidays. The moving average LOWESS is taken as the zero mark on the ordinate axis. Source: authors' calculations based on modelling and Rosstat data.

The data shown in the figure reveals that $70 \%$ of the excess deaths (49.6 thousand) occur in connection with the New Year, another 19\%, 7\% and 4\% of their number occur in connection with Christmas, the old New Year, and Epiphany respectively. It will be shown below that some of the excess deaths on Christmas days may be due to the dynamics of deaths from respiratory and digestive diseases.

\section{Excess mortality in January by cause}

The dynamics of deaths from causes of classes such as neoplasms, infectious diseases, and deaths from other causes did not show any changes in connection with the holidays. Excess deaths from causes of other classes in January are presented in Fig. 4 and Fig. 5. The largest increase on January 1 was recorded in relation to deaths from external causes, and the increase begins on December 28 (Fig. 4). An increase in the number of deaths due to diseases of the circulatory, respiratory, and digestive systems is recorded on January 1, but the peaks for these classes do not coincide: on January 2, there is a peak in the number of deaths from diseases of the circulatory system, on January 9 and 10 - from the two other causes. Additional peaks on January 7, 14, and 20 are characteristic of external causes. 


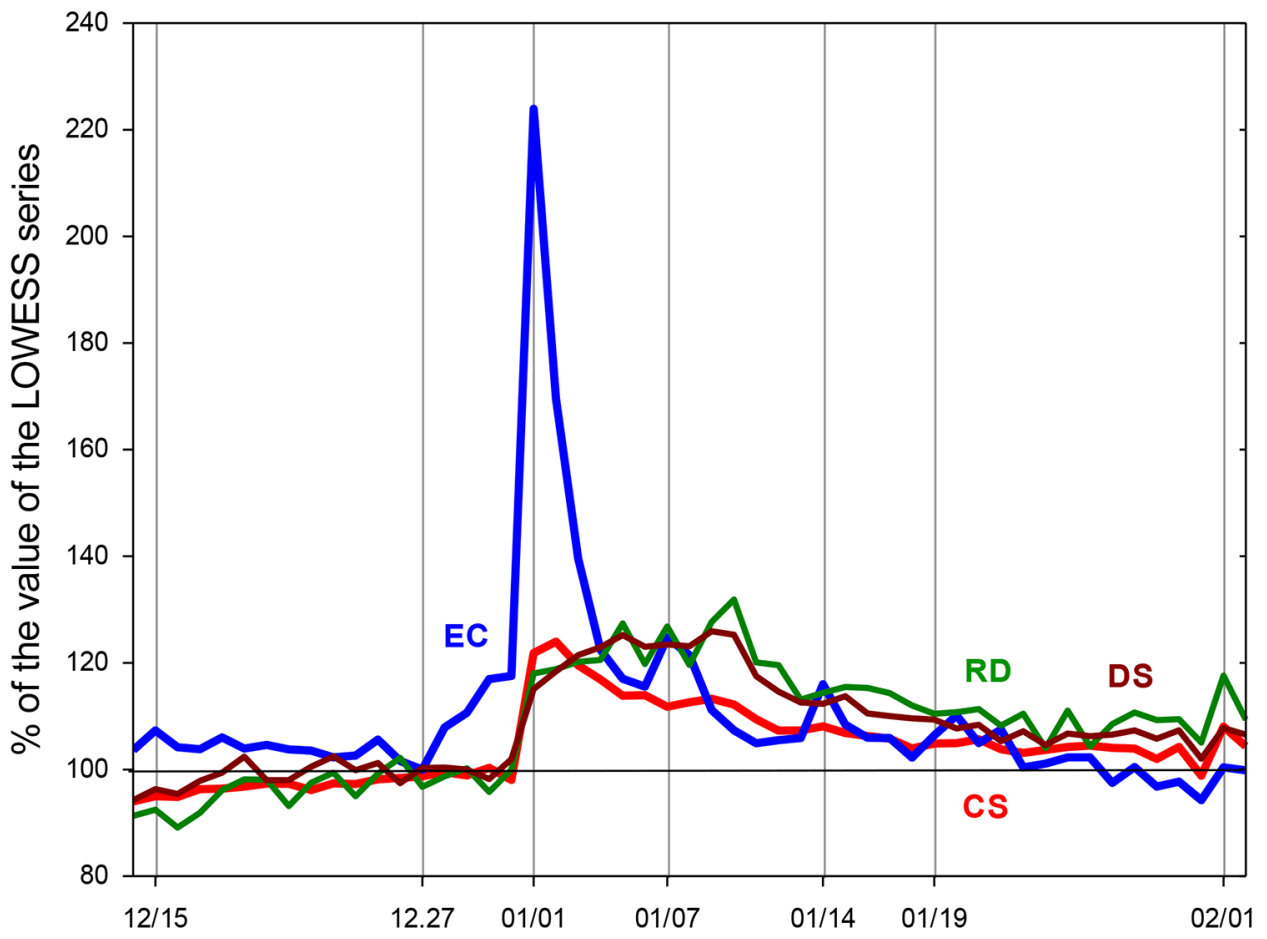

Fig. 4. The daily number of excess deaths in Russia from December 15 to February 1 , the sum of indicators for 2011-2019, \% of the LOWESS moving average which is taken as $100 \%$. Note: EC - external causes, CS - diseases of the circulatory system, RD - diseases of the respiratory system, DS - diseases of the digestive system. Source: authors' calculations based on modelling and Rosstat data.

The volumes of excess mortality by class of causes are presented in table 2 . It is important to note that the identification of «non-holiday» deaths on holidays using LOWESS seems to be accurate: their correlation (excluding non-holiday deaths) with the total number of deaths is significant $(\mathrm{r}=0.993 ; \mathrm{p}=0.0001 ; \mathrm{n}=7$ reasons; Kendall's $\tau$-correlation). In other words, «non-holiday» deaths on holidays adequately reflect deaths on non-holidays, which is a prerequisite for a satisfactory assessment of excess mortality.

The dynamics of mortality due to the three previously identified socially significant causes are presented in table 2 and Fig. 5. As can be seen from the estimates obtained, the number of homicides and alcohol poisonings begins to grow before the start of the holidays, after December 25. However, the peaks in all three series fall on January 1. For alcohol poisonings and homicides, the peaks are also well-pronounced on January 7, 14 and 19, while for suicides - only on January 7. These three causes of death showed the largest increase, from $21 \%$ to $101 \%$ (see table 2), while the main classes of causes increased from $9 \%$ to $13 \%$. In January, other groups of deaths from external causes also made an additional contribution to excess mortality from external causes (see «Other» in table 2). 


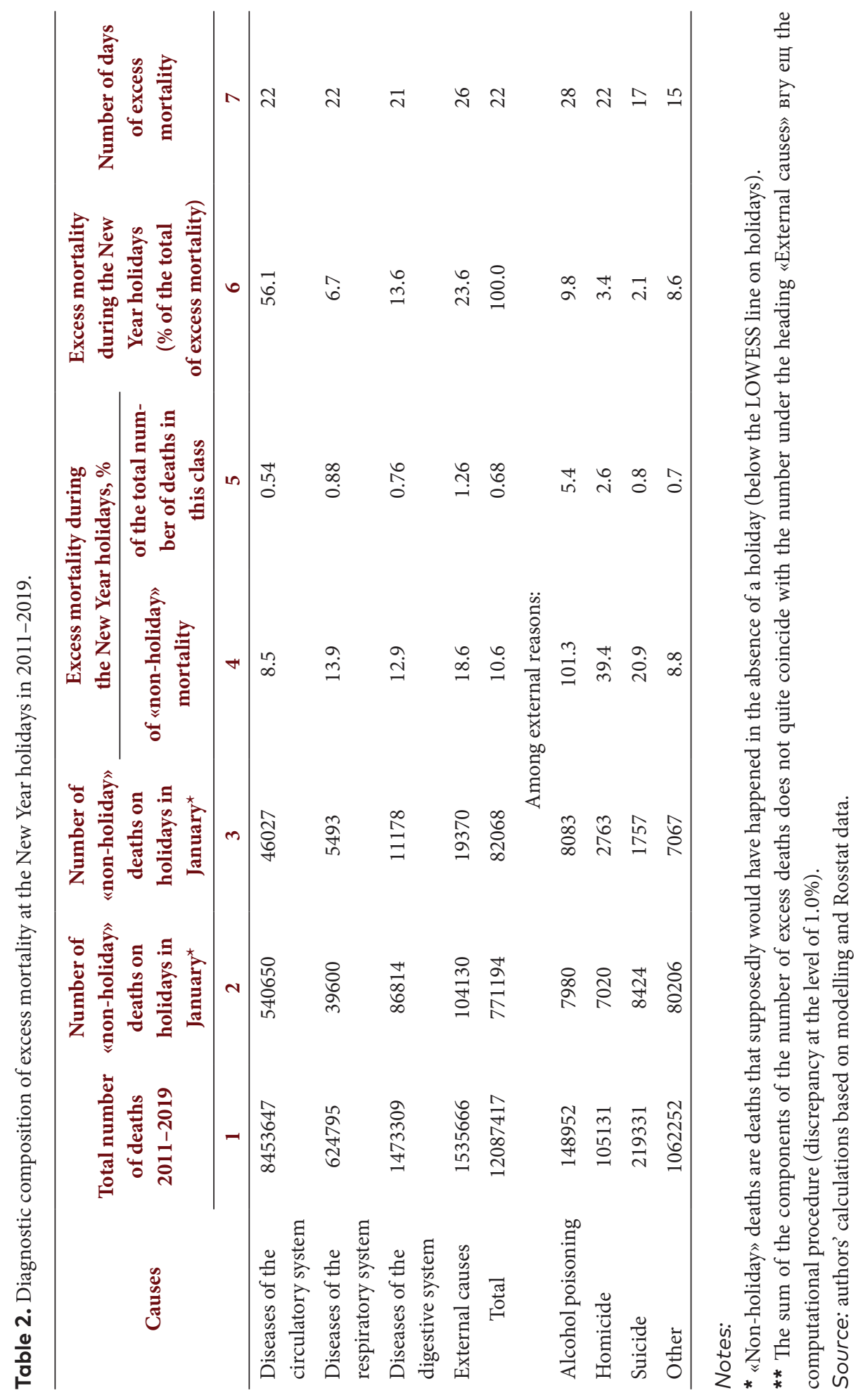




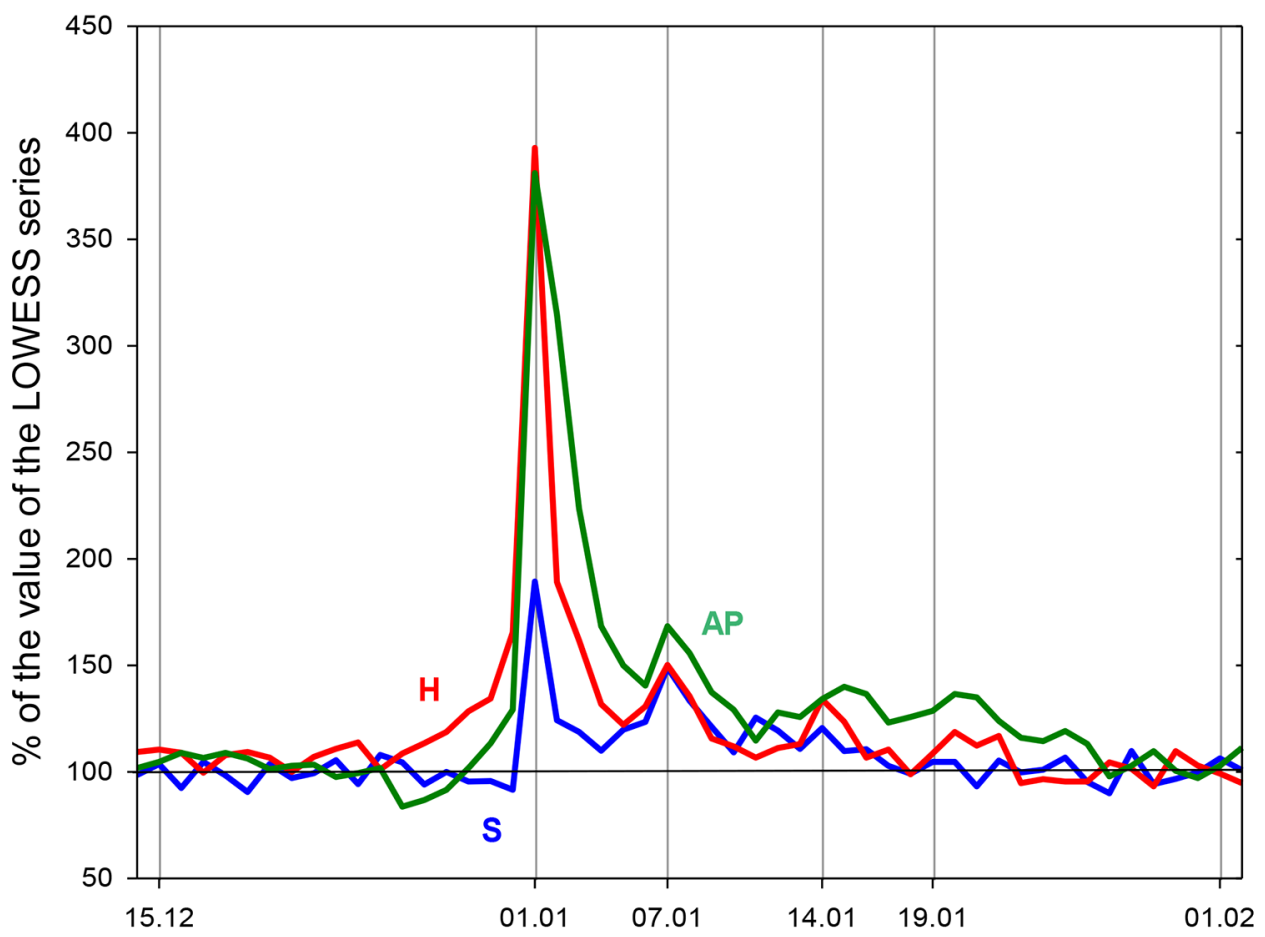

Fig. 5. Number of excess deaths in Russia from December 15 to February 1, the sum of indicators for 2011-2019, \% of LOWESS moving average taken as 100\%. Note: AP — alcohol poisoning, H homicide, S - suicide. Source: authors' calculations based on modelling and Rosstat data.

Before moving on to the next topic, it is important to answer the question: how does excess mortality for certain classes of causes of death on holidays correlate with mortality of the same classes beyond the holiday period? In other words, is excess mortality in January holidays proportional to non-holiday mortality? The authors address this issue graphically: Fig. 6 shows a scatter plot for two indicators, where non-holiday deaths are subtracted from the total value. In this case, three sets of variables are used: 1) full set of eight variables, 2) all variables excluding alcohol poisoning and external causes, 3 ) all variables excluding alcohol poisoning, external causes, and diseases of the circulatory system. As can be seen, in the second case, five variables form a linear regression ( $\mathrm{r}=0.800 ; \mathrm{p}=0.042 ; \mathrm{n}=5$; Kendall's $\tau$-correlation), and deaths from alcohol poisoning and from external causes lie beyond the 95\% confidence interval. The discovered effect can be explained by the large contribution of the diseases of the circulatory system; however, even without this indicator, alcohol poisonings and deaths from external causes remain beyond the $95 \%$ confidence interval.

Here, we can conclude that for the six classes and types of causes of death considered, there is a correlation between excess mortality on holidays and mortality on non-holidays, that is, the higher the mortality on plain days, the greater the excess mortality on holidays. For all external causes and alcohol poisoning in particular, this pattern is violated: excess mortality on holidays for these classes is significantly higher than one would expect based on mortality rates on plain days (see table 2, column 8 ). The number of homicides on holidays also increases compared to non-holiday period, but the observed values remain within the $95 \%$ confidence interval of the main group of causes. 


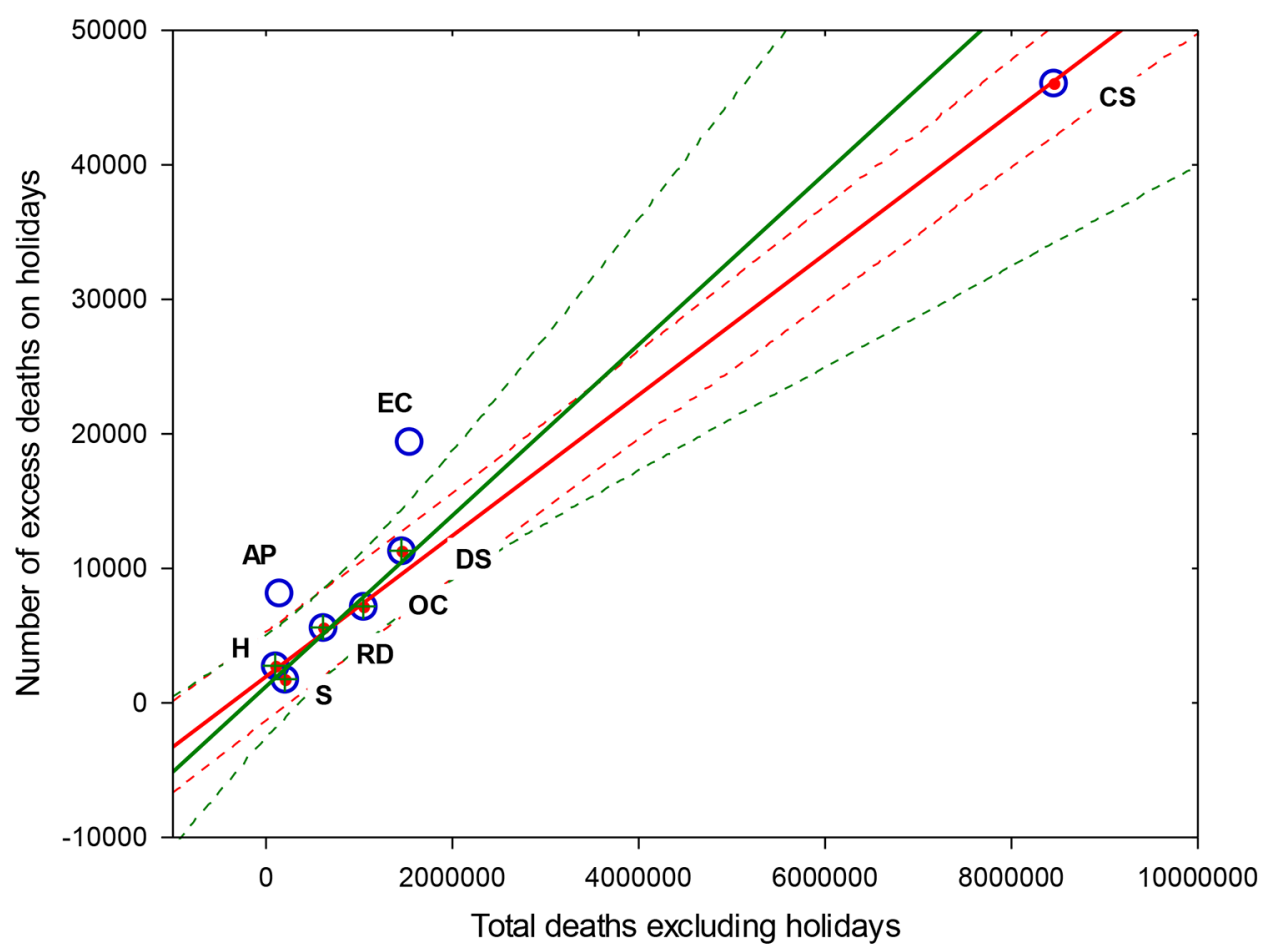

Fig. 6. Ratio of excess and total mortality for certain classes of causes of death. Note: CS - diseases of the circulatory system, RD - diseases of the respiratory system, DS - diseases of the digestive system, EC - all external causes, AP - alcohol poisoning, $\mathrm{H}$ - homicides, $\mathrm{S}$ - suicides, OC - other external causes. Blue circles in the diagram indicate all eight classes of causes of death, red dots indicate a set of causes without EC and AP (red regression line), crosses - a set of causes without CS, EC, and AP (green regression line). The dotted lines represent the 95\% confidence intervals. Source: authors' calculations based on modelling and Rosstat data.

\section{Age profile of excess mortality in January}

The analysis of mortality in terms of age structure reveals some disproportions. Thus, an increase in the number of deaths begins in the pre-holiday period on December 28 for those aged 15-29 and 30-44 years, but only on January 30 for 45-59-year-olds; at the same time, mortality peaks at all ages occur on January 1 . At the same time, the greatest relative increase is observed in the group of 15-29-year-olds (Fig. 7, table 3) and it gets lower with the transition to older age groups. Another important feature is that the slope of the decrease in excess mortality is approximately the same in the first three age groups (from 0 to 44 years), and then, with age, the curve becomes more flat, the reduction lasts longer (Table 3 ), and the peaks in holidays after January 1 become be less pronounced.

It is important to note that the increase in excess mortality in relation to LOWESS («nonholiday» mortality) decreases with age from $16.9 \%$ (0-14 years) to $5.1 \%$ (among those aged 75 and over; see table 3 ). The contribution to the total excess mortality, on the contrary, increases with age from $0.5 \%$ (0-14 years) to $32.1 \%$ ( $45-59$ years), after which it slightly decreases (down to $23.3 \%$ at the age of 75 and older). The same dynamics are observed in the duration of the period of excess mortality on holidays: it increases with age (table 3 ). 


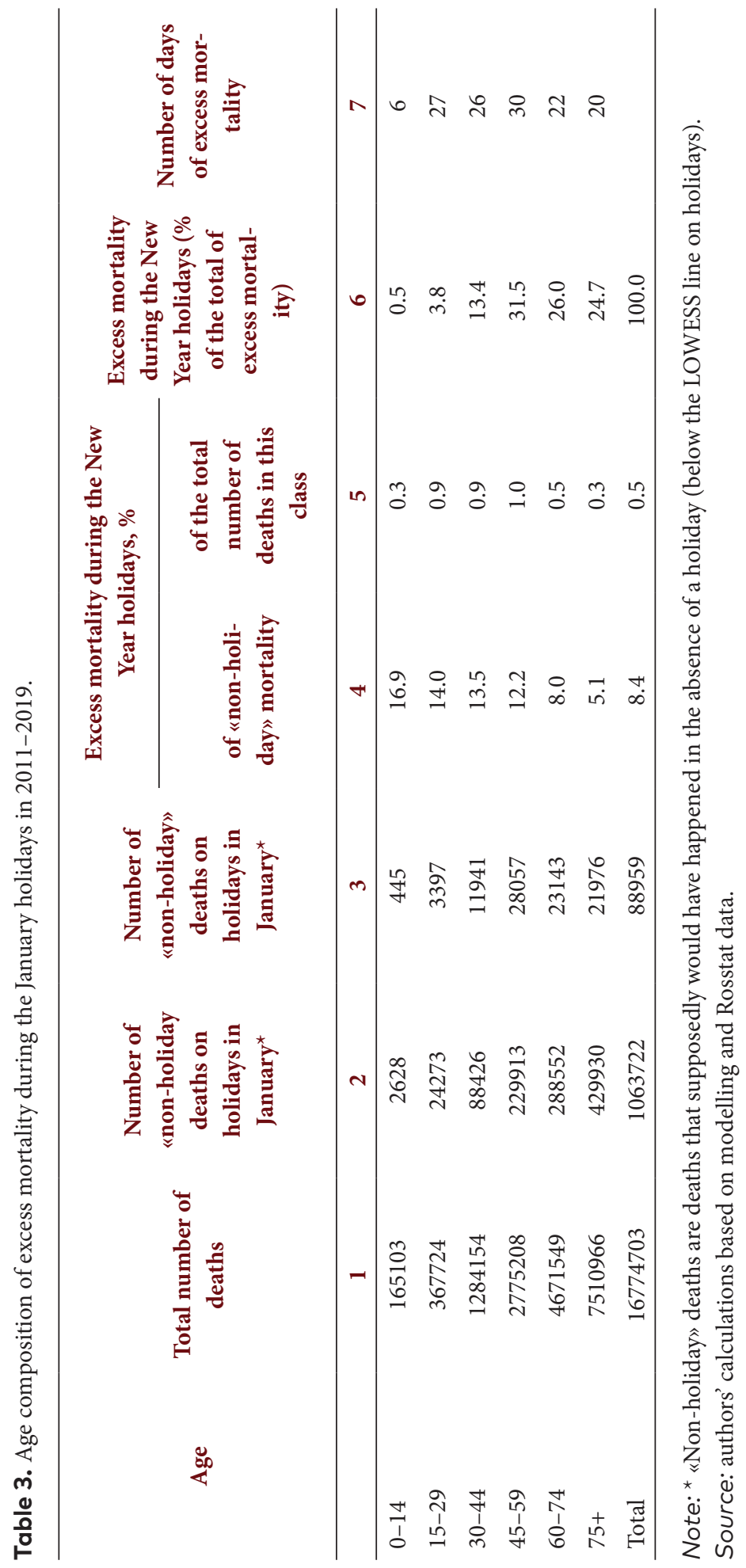




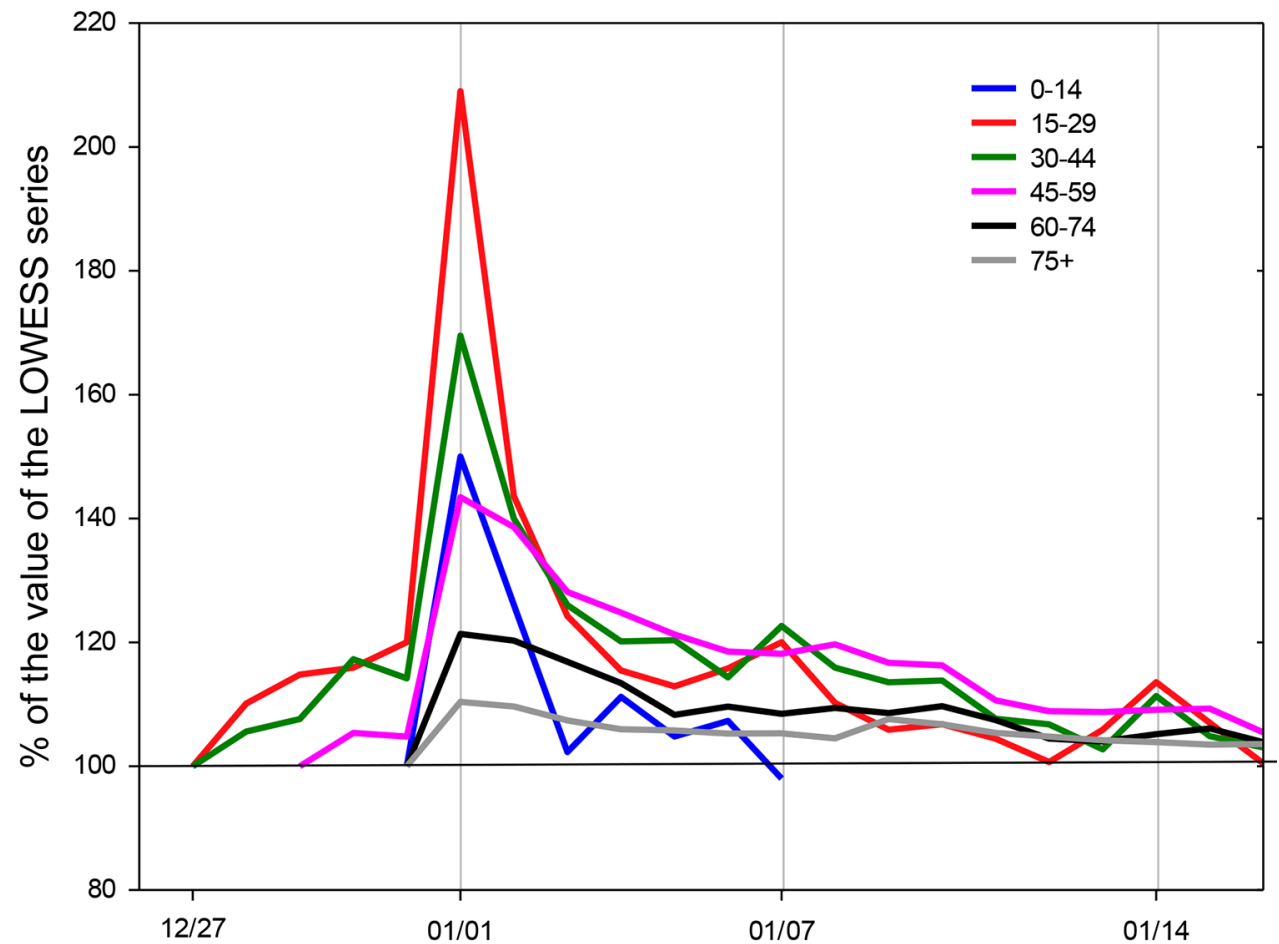

Fig. 7. Daily number of excess deaths in Russia from December 15 to February 1, sum of indicators for 2011-2019, \% of the LOWESS moving average taken as 100\%. Source: authors' calculations based on modelling and Rosstat data. 


\section{Sales of alcoholic beverages}

The congruence of the January 1 maximum of total mortality (Fig. 2) and of mortality due to the alcohol poisonings (Fig. 5) leads to the question of the relationship between excess mortality in January and alcohol abuse. To die from alcohol poisoning on January 1 , alcohol must be purchased no later than December 31. To analyze the dynamics of alcohol purchases, we regard two types of alcohol beverages, namely, vodka and wine, and track volume of the retail sales of vodka and wine by months in 2018-2019 together with the corresponding amount of pure alcohol estimated based on Rosstat coefficients: 0.3995 for vodka and 0.1184 for wine (Fig. 8).

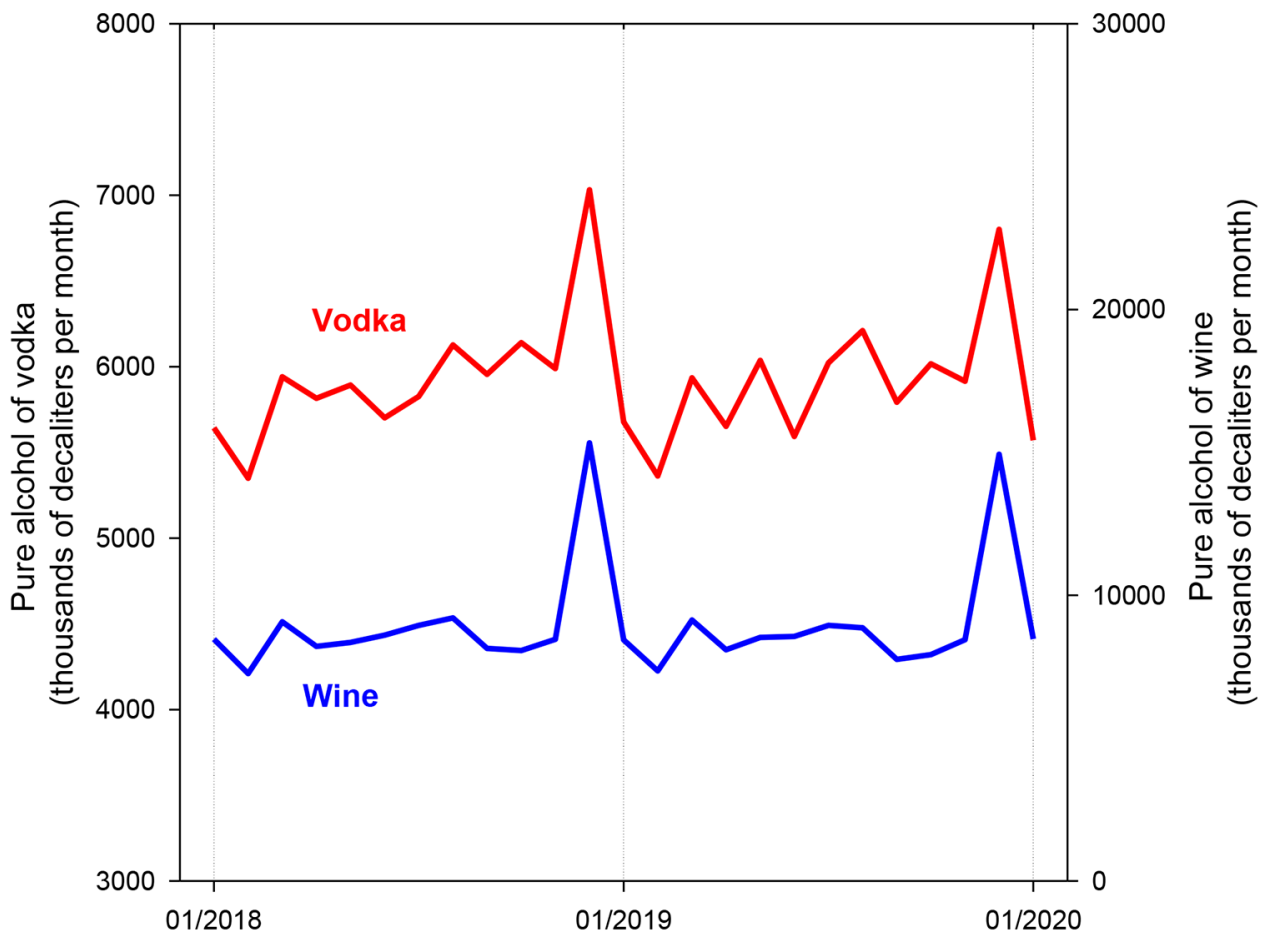

Fig. 8. Retail sales of vodka (left axis) and wine (right axis) from January 2018 to January 2020 estimated in pure alcohol volume. Source: authors' calculations based on Rosstat data.

Fig. 8 shows that the main source of alcohol in the country is vodka, and the annual maximum sales of both wine and vodka occur in December, on New Year's Eve. The pathogenic value of beer in comparison with vodka is insignificant due to the eightfold difference in alcohol concentration. Compared to November, the increase in wine sales in December amounted to 20.3\%, in vodka sales - to $25.6 \%$. However, in terms of alcohol content, vodka and wine sold in December correlate as 1:9. In absolute terms, the increase in vodka sales in December amounted to 8.5 million litres of alcohol or 21.3 million litres in vodka equivalent in one month. It is important to emphasize that $70 \%$ of alcoholic beverages are supplied to the population through retail trade. Earlier it was shown that the number of Internet queries for illegal delivery of vodka begins to increase sharply a week before the New Year and reach a maximum on December 31 (Nemtsov et al. 2021). Increased alcohol consumption in December may explain the rise in mortality during the January holidays; this will be discussed in more detail in the concluding section of the paper. 


\section{Research Limitations}

The principle adopted in the paper for determining the end of excess mortality period during the January holidays (the last day when mortality exceeds LOWESS after reaching the maximum) in two cases excluded excess mortality on holidays in the second half of January from consideration, which could understate the estimates obtained. In addition, some inaccuracy may have been caused by the principle of filling in the holiday gaps based on linear regression predictions.

The paper did not specifically investigate the various factors of excess mortality in January; the authors focus only on the topic related to alcohol consumption, including the statistics of sales of strong alcohol in December and correlating it with the dynamics of mortality from alcohol poisoning. To obtain a more accurate assessment of the role of this factor, as well as to study the influence of other factors, including overeating, on the dynamics of mortality during the holiday period, it is necessary to have a more detailed distribution of mortality by cause at the researchers' disposal and to conduct special studies with a wide range of parameters.

Due to the fact that January is the coldest month of the year (the average daily temperature in Russia is $-12^{\circ} \mathrm{C}$, while in December and February it is $-8^{\circ} \mathrm{C}$ and $-9^{\circ} \mathrm{C}$, respectively), during this period one can expect an increase in mortality due to the spread of influenza, acute respiratory diseases (ARD) and pneumonia. Deaths due to influenza and acute respiratory infections in January averaged 53 cases per year (data for 2011-2017, until 2011 deaths due to influenza and acute respiratory infections were recorded together with pneumonia). In connection with pneumonia, an average of 2.8 thousand deaths are recorded in January, which are distributed almost evenly throughout the month and are not concentrated at its beginning. At the same time, from our point of view, these deaths should not be excluded from calculations when assessing holiday losses, since the risk of developing pneumonia may also be associated with the level of alcohol consumption.

The presented study does not concern topics such as the distribution of excess mortality by sex (either in general or by causes of death and age), regional differentiation, the age distribution of mortality within the classes of causes, and the distribution of causes in age groups.

Finally, the main limitation of the study is the existing diagnostic inaccuracy when registering deaths in Russia, which has been repeatedly pointed out by representatives of the scientific and expert community. The related biases could have influenced the accuracy of calculations in some cases; however, it should not undermine the general conclusions of the paper.

\section{Key findings and discussion}

The results of this study confirmed the earlier conclusion that the greatest excess mortality during the holidays is observed in January (Nemtsov 2017; Nemtsov et al. 2021). The description of the internal structure of this mortality due to causes of death and the age of those who died on holidays is a novelty of this paper.

The authors use local polynomial regression or LOWESS moving regression, which is a generalization of moving average and polynomial regression. This standard nonparametric procedure does not require preliminary assumptions about the distribution pattern and al- 
lows adjustments for seasonality and other trends (e.g., winter increases in mortality). The LOWESS procedure allowed not only to determine whether the mortality rate increased during the New Year holidays, but also to measure excess mortality during this period.

In January, the excess mortality was dominated by diseases of the circulatory system ( $56 \%$ or 46 thousand in 2011-2019; table 2, column 6), however, in relation to "non-holiday» deaths of this class during holidays, the increase was the smallest $(8,5 \%)$. In addition, excess mortality from diseases of the circulatory system gave the minimum increase in the total number of deaths from causes of this class (0.54\%; table 2, column 5). Thus, a significant contribution of mortality from diseases of the circulatory system to the New Year's excess mortality is determined by the initially high level of this pathology, and the holidays and accompanying feasts with alcohol serve as a trigger for its aggravation. This is evidenced by a sharp increase in mortality on January 1 ; it is unlikely that a new pathology in such an amount was formed in a single day. In other words, on December 31, a large proportion of people sit down at the New Year's table with the risk of dying from diseases of the circulatory system, and $0.54 \%$ of them do die (table 2 ) as a result of the holiday and the accompanying heavy eating and alcohol consumption. It could be said that the risks of dying at the New Year from a cardiovascular pathology are largely personified. Such thanatogenesis, most likely, determines the closeness of the shares of cardiovascular mortality both in total and excess indicators (50.4\% and 56.1\%, respectively; tables 1 and 2), and the slight difference is determined by the fact that in the second case classes of deaths that did not show an increase in connection with the holidays are excluded. It is important to note that more people with cardiovascular disease die on holidays than on plain days.

As noted above, excess mortality during the New Year and Christmas holidays was also recorded in a number of countries of Western culture, including the United States, where cardiovascular mortality, as in Russia, was dominant (Phillips et al. 2004; Phillips et al. 2010). The difference was that the rise in excess mortality in the United States revealed itself in two short peaks of one to two days in length, with declines in between. Moreover, the first peak (Christmas) was larger than the second (New Year), while in Russia excess mortality at Christmas is minimal.

We should emphasize the role of the first day of the holidays in the thanatogenesis of cardiovascular and other classes and types of death. In some cases, a small increase in mortality begins a few days before the start of the holiday (such dynamics are observed for external reasons and in the middle age group; Fig. 5 and 7), but a sharp increase is observed only on January 1 (Fig. 2, 4, 5, 7). A similar picture is shown in other studies, both in Russia (Barabash et al. 2010) and abroad (Milne 2005; Phillips et al. 2004; Phillips et al. 2010; Bridges 2004; Bergen and Hawton 2007). Some of the observations are surprising. The same «accuracy» in time is characteristic of unintentional deaths from bullets fired into the air on January 1 in the southern states of the United States and countries of South America (Rapkiewicz et al. 2014; Rodriguez and Mirabal-Colon 2004). The observed distribution of deaths on holidays designates December 31 as the last day of preventive measures, and their beginning should be planned a month before; however, it is better to begin even earlier in order to have time to reduce the availability of strong alcohol in December as one of the alleged reasons for the increase in mortality during the New Year (Fig. 8).

The conclusions described in relation to mortality from diseases of the circulatory system are also valid for the analysis of mortality from other somatic causes; the New Year's feast mainly complicates the previous chronic diseases of the respiratory and digestive organs, adding 5.5 and 11.1 thousand deaths to «non-holiday» deaths respectively (table 2). The excess mortality 
of these two classes in January is also proportional to the total number of deaths from them (3.7\% and $8.8 \%$, table 1). The difference in the dynamics of cardiovascular pathology from the other two classes of pathologies (Fig. 4) is determined by its greater severity and transient development of the condition: in patients with myocardial infarction and stroke, the average duration of hospitalization is 3 days (and median duration is 0.25 days or 6 hours; (Odintsova et al. 2017)). The course of diseases of the respiratory and digestive organs, and with this an increase in mortality, stretches for 10 days, after which the indicators sharply decrease; the return to the «non-holiday» indicators is observed, however, only on days 21-22 (Fig. 4). The described decrease on the tenth day is probably due to the end of the holidays and the restoration of the potential of the healthcare service. In addition, it cannot be ruled out that the prevalence of acute respiratory infections affects the dynamics of respiratory diseases during 10 days of January, but in general, the excess mortality rate on the New Year's holidays is proportional to the previous mortality, which is clearly seen in Fig. 6. An American study (Phillips et al. 2010) also found an increase in mortality from respiratory and digestive diseases, in the form of two short peaks at Christmas (+ 10.5\% and + 4.6\%) and the New Year (7.5\% and $10.3 \%)$.

An analytical scheme with personalized risks, broken down into three classes of somatic causes, is less suitable for external causes: only a part of these deaths is predetermined by antecedent pathology. Thus, the risk of death due to alcohol poisoning is higher in patients with alcoholism (Ugryumov 1990; Shustov 2004: 214) and drug addiction (Lynch et al. 2020). The contribution of previous alcoholism to other types of external causes is doubtless; for example, it can aggravate the effects of exposure to low temperatures (Yugov 2003: 166) and increase the likelihood of homicides (Nemtsov 2019). The risk of suicide is very high in patients with depression (Cavanagh et al. 2003) and other mood disorders (Lynch et al. 2020). However, in addition to these personalized risks, in the case of external causes, there are risks spread among the rest of the population. Judging by the fact that the data do not show a correlation between the share of these deaths in excess and total mortality, on holidays mortality from external causes is largely determined by distributed risks, as a result of which their share grows from $12.6 \%$ on plain days to $23.6 \%$ on holidays (table 2 ; an increase of $11.0 \%)$. This feature is even more pronounced in the case of alcohol poisoning: on holidays their number doubles (grows by $101.3 \%$ ), which makes a significant contribution to mortality from external causes. Homicides only partially fit into this scheme, and this requires further research on the ratio of risks in holiday mortality.

The analysis of the distribution of excess mortality by age groups largely reinforces the conclusions drawn on the basis of the distribution by cause: over $80 \%$ of excess mortality occurs in people over 45 , who are most burdened with pathologies, and within this group in people aged 45-59 with the most severe alcohol consumption (Lebedeva-Nesevrya et al. 2017). The connection with age is also manifested in the fact that with its increase, the mortality reduction curve progressively flattens after January 1 ; representatives of young cohorts cope with the pathology that arose during the holiday faster. In addition, it can be noted that after January 10, mortality decreases markedly in older ages (Fig. 7), while in younger groups (15-44 years old) during this period, excess mortality increases on the holidays of January 14 and 19. In this group, the increase in excess mortality is most clearly manifested during the preceding January holidays (Fig. 7).

The results of an American study (Phillips et al., 2010) show a relatively small increase in mortality at Christmas (6.3\%) and the New Year (3.2\%). In general, in the United States in 1979-2004 excess mortality during the New Year and Christmas period amounted to 42.3 thousand deaths or 1.6 thousand deaths per year, and this is lower than in Russia (9.9 
thousand deaths per year). Comparison of these indicators requires caution, since in the late 1990s the United States faced an onset of the opioid pandemic (see (Centers for Disease Control...)) and, accordingly, a significant increase in mortality, and in Russia, in 20112019 there was a decrease in mortality. However, such a ratio of trends should have brought the indicators closer together rather than diluted them.

Identifying the factors that determine excess mortality requires a special study, but it can be assumed that one of them is an increase in the consumption of strong alcohol on holidays, both legal (Fig. 7) and illegal (Nemtsov et al. 2020). This is evidenced, in particular, by a twofold increase in mortality from alcohol poisoning on holidays. In general, a third of the identified excess deaths from external causes $(30.8 \%)$ during the holiday period are alcohol poisoning, homicide, and suicide. According to our estimates, the number of deaths from these causes during the observed period increased in January by $101 \%, 39 \%$ and $21 \%$, respectively. The largest increase in this group of deaths is accounted for by alcohol poisoning. It is known that patients with alcoholism prevail among those who died from alcohol poisoning (Ugryumov 1990; Shustov 2004: 214). The risk of dying of this cause can occur at any time, but the twofold increase in mortality from alcohol poisoning on holidays appears to be a consequence of a twofold increase in alcohol consumption or the number of heavy drinkers in the cohort of people from which those who die of poisoning on plain days are recruited. Undoubtedly, the increase in alcohol consumption also affects the dynamics of homicides and suicides, as well as the dynamics of mortality from all other causes, which determines the excess mortality in the January holidays.

On the basis of the presented analysis, it is difficult to explain why, under similar conditions on January 1 (feast, alcohol), the proportionality between excess mortality and mortality on plain days is violated in the case of external causes. It can only be assumed that the previous somatic pathology restrains the abuse, including alcohol, and cardiovascular diseases play a greater role in this sense in comparison with the pathologies of the respiratory and digestive systems (table 2).

It can be assumed that the January damage is accounted for not only by excess mortality, but also by excess morbidity. It is important to emphasize that morbidity and mortality in January are preventable events. Informing the population about the fatal consequences and reducing the availability of strong alcohol, the maximum sales of which are in December, can reduce the damage during the January holidays.

It should also be noted that the discrepancy between the excess mortality rates calculated in two ways - by causes and by age ( 82.1 thousand and 89.0 thousand; $10.6 \%$ and $8.4 \%$; see tables 2 and 3) - requires clarification. In the first case, three classes of causes were excluded from consideration (27.9\% of all deaths), which did not reveal excess mortality in total by classes; in the second, deaths from all causes were taken into consideration. The resulting difference of 6.9 thousand deaths is probably due to the fact that there was an increase in mortality on holidays by the excluded from consideration causes. Therefore, the final result of the work should be as those obtained by age: excess mortality during the January holidays amounted to 89.0 thousand over 9 years; the increase in mortality due to holidays and concomitant overconsumption and abuse, primarily alcoholic, amounted to $8.4 \%$.

\section{Acknowledgments}

The paper was prepared within the framework of the HSE programme of fundamental research. 


\section{Reference list}

Barabash OL, Altarev SS, Fomina NV (2010) Neblagopriyatnoe vliyanie perioda novogodnikh prazdnikov na pokazateli obshchei i kardiovaskulyarnoi smertnosti [Unfavorable influence of the New Year holidays period on the indicators of general and cardiovascular mortality]. Kardiologiya [Cardiology] 50(11): 35-9. (in Russian)

Bergen H, Hawton K (2007) Variation in deliberate self-harm around Christmas and New Year. Social Science \& Medicine 65(5): 855-67. https://doi.org/10.1016/j.socscimed.2007.04.004

Bridges F (2004) Rates of homicide and suicide on major national holidays. Psychological Reports 94 (2): 723-4. https://doi.org/10.2466/pr0.94.2.723-724

Cavanagh J, Carson A, Sharpe M, Lawrie S (2003) Psychological autopsy studies of suicide: A systematic review. Psychological Medicine 33(3): 395-405. https://doi.org/10.1017/s0033291702006943

Cleveland W, Devlin S (1988) Locally weighted regression: An approach to regression analysis by local fitting. Journal of the American Statistical Association 83(403): 596-610. http://dx.doi. org/10.2307/2289282

Kloner R, Poole W, Perritt R (1999) When throughout the year is coronary death most likely to occur? A 12-year population-based analysis of more than 220000 cases. Circulation 100(15): 1630-4. https://doi.org/10.1161/01.CIR.100.15.1630

Knight J, Schilling C, Barnett A, Jackson R, Clarke P (2016) Revisiting the "Christmas Holiday Effect" in the Southern Hemisphere. Journal of the American Heart Association 5(12): e005098. https:// doi.org/10.1161/JAHA.116.005098

Lebedeva-Nesevrya NA, Zhdanova-Zaplesvichko IG, Rerke VI, Barg AO (2017) Potreblenie alkogolya kak faktor riska zdorov'yu naseleniya: obzor rossiiskikh issledovanii [Alcohol consumption as a risk factor for public health: a review of Russian studies]. Analiz riska zdorov'yu [Health Risk Analysis] 4: 147-60. URL: https://elibrary.ru/download/elibrary_32281172_84749276.pdf (in Russian)

Lynch FL, Peterson EL, Lu CY, Hu Y, Rossom RC, Waitzfelder BE, Owen-Smith AA, Hubley S, Prabhakar D, Williams LK, Beck A, Simon GE, Ahmedani BK (2020) Substance use disorders and risk of suicide in a general US population: a case control study. Addiction Science \& Clinical Practice 15(14). https://doi.org/10.1186/s13722-020-0181-1

Milne E (2005) Mortality spike at New Year but not Christmas in North East England. European Journal of Epidemiology 20(10): 849-54. URL: https://www.jstor.org/stable/25047548

Nemtsov AV (2017) Smerti v yanvare - Rossiya: 2004-2016 [Deaths in January - Russia: 2004-2016]. Sotsial'nye aspekty zdorov'ya naseleniya [Social Aspects of Population Health] 58 (6). https://doi. org/10.21045/2071-5021-2017-58-6-2_(in Russian)

Nemtsov AV (2019) Alkogol'naya sostavlyayushchaya ubiistv v prazdniki, Rossiya, 2000-2017 gg. [Alcohol component of murders on holidays, Russia, 2000-2017]. Voprosy narkologii [Narcology issues] 176(5): 31-44. https://doi.org/10.47877/0234-0623_2019_5_31_(in Russian)

Nemtsov AV, Gridin RB, Cho EG (2020) Otsenka potrebleniya nelegal'nogo alkogolya po zaprosam v internete [Estimation of consumption of illegal alcohol by inquiries on the Internet]. Voprosy narkologii [Narcology issues] 186(3): 67-77. https://doi.org/10.47877/0234-0623_2020_3_67_(in Russian)

Nemtsov AV, Simonov AN, Fattakhov TA, Gridin RV (2021) Izbytochnaya smertnost' v Rossii v prazdnichnye dni [Excess mortality in Russia on holidays]. Demograficheskoe obozrenie [Demographic Review] 8(1): 16-43. https://doi.org/10.17323/demreview (in Russian)

Odintsova OA, Malyavin AG, Zayratyants OV (2017) Prediktory razvitiya pnevmonii u patsientov s ostrymi sosudistymi katastrofami [Predictors of pneumonia in patients with acute vascular catastrophes]. Arkhiv vnutrennei meditsiny [Archives of Internal Medicine] 7(1): 55-9. https://doi. org/10.20514/2226-6704-2017-7-1-55-59_(in Russian) 
Phillips D, Barker G, Brewer K (2010) Christmas and New Year as risk factors for death. Social Science \& Medicine 71(8): 1463-71. URL: https://pages.ucsd.edu/ dphillip/christmas_and_new_year_as_ risk_factors_for_death_phillips_barker_brewer.pdf

Phillips D, Jarvinen J, Abramson I, Phillips R (2004) Cardiac mortality is higher around Christmas and New Year's than at any other time: The holidays as a risk factor for death. Circulation 110(25): 3781-8. https://doi.org/10.1161/01.CIR.0000151424.02045.F7

Rapkiewicz AV, Shuman MJ, Hutchins KD (2014) Fatal wounds sustained from "falling bullets": Maintaining a high index of suspicion in a forensic setting. Journal of Forensic Sciences 59(1): 268-70. https://doi.org/10.1111/1556-4029.12258

Rodriguez I, Mirabal-Colon B (2004) New Year's Eve injuries caused by celebratory gunfire - Puerto Rico. CDC Morbidity and Mortality Weekly Report 53(50): 1174-5. URL: https://pubmed.ncbi. nlm.nih.gov/15614232

Shustov DI (2004) Autoagressiya, suitsid i alkogolizm [Autoaggression, suicide and alcoholism]. Moscow: Kogito-Center. URL: http://www.studmedlib.ru/book/589353154X.html (in Russian)

Ugryumov AI (1990) Organnaya patologiya i prichiny smerti bol'nykh zloupotreblyayushchikh alkogolem [Organ pathology and causes of death of alcohol abusers]. Voprosy narkologii [Narcology issues] 3: 47-51. (in Russian)

Yugov KM (2003) Sudebno-meditsinskaya otsenka stepeni alkogol'noi intoksikatsii pri smerti ot pereokhlazhdeniya [Forensic medical assessment of intoxication in death from hypothermia] / diss. kand. med. nauk. Barnaul. (in Russian)

Zhaksymbaev M (2012) Dinamika smertnosti ot ubiistv v Rossii [Dynamics of mortality from homicide in Russia]. Demoscope Weekly 535-536. URL: http://www.demoscope.ru/weekly/2012/0535/ analit09.php (in Russian)

\section{Other data sources}

Centers for Disease Control and Prevention. Understanding the Epidemic. https://www.cdc.gov/opioids/basics/epidemic.html (accessed November 16, 2021)

Roznichnaya prodazha alkogol'noi produktsii v natural'nom vyrazhenii [Retail sale of alcoholic beverages in volume terms]. Rosstat. URL: https://www.fedstat.ru/indicator/57614_(accessed January $10,2020)$

\section{Information about the authors}

- Alexander Vikentievich Nemtsov, Doctor of Medicine, Leading Specialist, National Research Center of Narcology of the Ministry of Health of the Russian Federation. E-mail: nemtsov33@gmail.com.

- Timur Asfanovich Fattakhov, Research Fellow, Vishnevsky Institute of Demography, National Research University Higher school of economics. E-mail: timur300385@mail.ru. 